\title{
Teachers' Self-Efficacy, Sentiments, Attitudes, and Concerns about the Inclusion of Students with Developmental Disabilities
}

\author{
Angela Montgomery \\ Abbotsford (BC) School District \#34 \\ Pat Mirenda \\ University of British Columbia
}

\begin{abstract}
This study examined relationships between three factors related to teacher selfefficacy (use of inclusive instruction, collaboration with others, and managing disruptive behaviour) and practicing teachers'sentiments, attitudes, and concerns about inclusive education of students with developmental disabilities. We calculated Pearson product-moment correlations to examine individual associations and conducted a series of multiple regression analyses to determine which associated factors, when considered simultaneously, were most predictive. Results indicated that higher self-efficacy for collaboration was the only predictor associated with more positive sentiments and attitudes and with fewer concerns about inclusive education for students with developmental disabilities. The results replicate the findings of a previous study on this topic and highlight the importance of both pre-and in-service education aimed at providing educators with dispositions and skills related to effective collaboration with parents and other members of a school-based team.
\end{abstract}

The essential tenet of inclusive education is that students with special needs receive the instruction, resources, and supports that are necessary for them to participate fully with their peers in the general education classroom. Although specific definitions vary somewhat, inclusion typically includes at least three components: students attend neighbourhood schools, are educated with their same-age peers, and participate actively in both the curricular and social life of the classroom (de Boer, Pijl, \& Minnaert, 2011; Hammond \& Ingalls, 2003; Timmons, 2006). In Canada, the 2006 Participation and Activity Limitation Survey [PALS] reported that $56.7 \%$ of students with special needs ages 5-14 were enrolled in general education classrooms, compared to $26.9 \%$ and $16.2 \%$ who were in part-time and full-time special education settings, respectively (Statistics Canada, 2007). 
In British Columbia, students with developmental disabilities (e.g., intellectual disabilities, autism spectrum disorder, and physical or multiple disabilities) account for over one-third of all students with special needs in public and independent schools combined. In the 2012/2013 school year, approximately 20,000 students (3.2\% of the student population) had a developmental disability (British Columbia Ministry of Education, 2013). While no classroom placement figures are available for British Columbia, the 2006 PALS survey found that $78.2 \%$ of Canadian students with "severe" or "very severe" disabilities were placed in full-time special education settings, including more than half (53\%) of all students with developmental disabilities (Statistics Canada, 2007). This disproportionate figure is notable in light of a 2009 systematic review of research comparing the academic outcomes of students with intellectual disabilities in inclusive settings with their counterparts in special education settings (Canadian Council on Learning, 2009). Across four studies, 17 comparisons were calculated - 15 of which favoured inclusive settings, with moderate to large effect sizes. Several additional studies have also documented the social, academic, and adaptive skill benefits of inclusive classrooms for students with developmental disabilities (e.g., Dessemontet, Bless, \& Morin, 2012; Katz \& Mirenda, 2002a, 2002b; McDonnell et al., 2003).

At least four factors affect the extent to which students with developmental disabilities are likely to be included: systems issues, disability-specific issues, support factors, and teacher factors. We examine each of these briefly in the sections that follow.

\section{Systems Issues}

Systems factors refer to factors that are controlled by the various administrative arms of the education system and affect how schools are run. One of the key indicators of successful inclusion is the existence of a school community that recognizes and supports diversity and individual differences, and that establishes a climate to facilitate membership and belonging for all (Lohrmann \& Bambara, 2006). School administrators play an especially important leadership role in this regard by articulating support for the philosophy of inclusion and by enacting such support in practical, meaningful ways. This includes, for example, attending individual student meetings, providing support for inclusive initiatives and programs, recruiting and retaining staff who are supportive of inclusion, and using data to monitor the progress and impact of inclusive education initiatives (Horne \& Timmons, 2009; Kugelmass, 2001). In a survey by Horne and Timmons (2009), $100 \%$ of teachers agreed that principals' support is needed to make inclusion a success. Conversely, in a study by Hammond and Ingalls (2003), 94\% of teachers agreed that inclusion could not be implemented effectively without administrative support.

\section{Disability-Specific Issues}

Students with disabilities have varied strengths and weaknesses and they require diverse academic and behavioural supports. Thus, the nature of a student's disability and related educational needs may also affect teachers' attitudes towards inclusion. It seems that, in general, teachers may be more willing to include students with outward signs of disability compared to those with less obvious indicators (particularly those with emotional/behavioural challenges). For example, in a recent review, de Boer et al. (2011) cited the results of several studies that found a greater willingness on the part of teachers to include students with physical disabilities compared to those with moderate to severe emotional/behaviour disorders. One of the reasons for this is that teachers may view students with more obvious signs of disability (e.g., the need for a wheelchair) as having a reason or "excuse" for needing additional support (Cook \& Cameron, 
2010; Cook, Tankersley, Cook, \& Landrum, 2000). In contrast, Gilmore, Campbell, and Cuskelly (2003) focused on teachers' attitudes toward students with Down syndrome and found that only $20 \%$ believed that regular classrooms are the best place for these students. While teachers recognized the educational, social, and emotional benefits of inclusive settings, only $24 \%$ felt that a regular primary class with children of the same age was appropriate, and $28 \%$ believed that students with Down syndrome should be educated in separate schools. This suggests that the "obvious disability excuse" may not extend to this population of students with special needs, although more research is needed to explore this issue.

\section{Support Factors}

Teachers are responsible for many tasks throughout the school day, including academic instruction, conducting assessments and evaluations, providing remedial support, and preparing classroom and instructional materials. When teachers are asked to do something new (e.g., teach a student with a disability), they may need to spend extra time adapting or modifying existing lessons and/or creating new curricular materials, at least initially. In one study (i.e., Horne \& Timmons, 2009), 95\% of teachers indicated that they were concerned or very concerned about having enough planning time to meet the needs of all of their students. In several studies (i.e., Kent-Walsh \& Light, 2003; Lohrmann \& Bambara, 2006; Soto, Müller, Hunt, \& Goetz, 2001), teachers in inclusive classrooms identified the need for additional time in order to plan and prepare adaptive materials, implement new teaching techniques or programs, and learn how to use assistive technology or augmentative communication devices. Finding creative ways to provide additional planning time is often critically important in order for teachers to take ownership of students who may require more time for support.

The ability to collaborate productively has also been identified by both teachers and administrators as a crucial component of successful inclusion (Daane, Beirne-Smith, \& Latham, 2001; Lohrmann \& Bambara, 2006; Monahan, Marino, \& Miller, 1996). Soto et al. (2001) identified a number of key components of effective collaboration, including having regular team meetings, establishing common goals, including a variety of educational personnel with the necessary expertise, and establishing a team leader. All of these components require additional time and skills that are not necessarily in teachers' repertoires. In addition, general education teachers may feel apprehensive about working with special education teachers who are in the position of observing them as they teach students with special needs (Daane et al., 2001; Lohrmann \& Bambara, 2006). In one study (i.e., Monahan et al., 1996), 67\% of teachers said that they preferred to send students to a special education classroom rather than have special education teachers work in their classrooms. In another study (i.e., Hammond \& Ingalls, 2003), 82\% of teachers believed that general and special education teachers did not collaborate at a level that was adequate to support students in their schools.

\section{Teacher Issues}

Teachers are the key players in any educational system; not only do they work most closely with individual students, but they are also responsible for designing and implementing inclusive environments at the classroom level. Thus, it makes sense that teachers who have negative sentiments about people with disabilities in general are likely to have negative attitudes towards inclusion and may experience difficulty working with and providing learning opportunities for students with disabilities. Surprisingly, very few studies have addressed this issue. One exception was a study by Soto et al. (2001) that examined the inclusion of students with severe speech and 
physical impairments. Focus group participants identified having "discomfort with or fear of disability" (p. 67) as a barrier to inclusive education and noted that "overcoming fear of disability" (p. 68) was essential for establishing an inclusive classroom.

Teachers' view of their responsibility for student learning appears to be another factor that affects inclusion, and may differ across general and special education teachers. Jordan, Schwartz, and McGhie-Richmond (2009) noted that teachers who take ownership for the education of students with special needs are more effective at teaching all students and that "the difference between effective and ineffective inclusion may lie in teachers' beliefs about who has primary responsibility for students with special education needs" (p. 541). In one study (i.e., Monahan et al., 1996), only about $50 \%$ of general education teachers believed that they were primarily responsible for educating students with special needs in their classrooms. In this same study, the majority of general education teachers said that they preferred to send students with special needs to special education classrooms rather than have special education teachers provide support in their classrooms. Similarly, Blecker and Boakes (2010) and Daane et al. (2001) found that special education teachers believed that general education classroom teachers do not have the primary responsibility for educating students with special needs and were more likely to cluster students with special needs in separate settings. Clearly, beliefs and attitudes such as these are not likely to result in successful inclusion.

In addition, numerous studies have noted that training and experience with the philosophy of inclusion, special education in general, and practices related to inclusive education positively relate to teachers' attitudes (e.g., de Boer et al., 2011). Teachers' perceptions of self-efficacy regarding their ability to teach in inclusive settings appear to be similarly related. Teachers often report that lack of training (both pre-service and in-service) contributes to their lack of selfconfidence (Wilkins \& Nietfeld, 2004). Conversely, teachers who feel confident in their ability to include all students often identify their experiences and training in special education as factors that contribute to this positive attribution (Lohrmann \& Bambara, 2006). This relationship was measured directly in a recent study of primary and secondary teachers in Finland and South Africa, using two psychometrically sound measures - the Teacher Efficacy for Inclusive Practices (TEIP) scale (Sharma, Loreman, \& Forlin, 2011) and the Sentiments, Attitudes, and Concerns about Inclusive Education-Revised (SACIE-R) scale (Forlin, Earle, Loreman, \& Sharma, 2011). Results indicated that teachers' self-efficacy, in general, and self-efficacy with regard to collaboration skills, in particular, were significantly related to their overall attitudes about inclusion (Savolainen, Englebrecht, Nel, \& Malinen, 2012).

In summary, while some studies have investigated a range of factors that influence teachers' attitudes about and willingness to support inclusive education in general, gaps remain in the literature. Specifically, most studies about teachers' attitudes towards inclusion have focused on students with emotional/behaviour disorders, learning disabilities, and/or other, relatively "mild" disabilities, rather than on those with intellectual and other developmental disabilities. Similarly, although teacher self-efficacy has been identified as an important influence on teachers' attitudes toward inclusion, the relationship between these attitudes and teacher self-efficacy has been explicitly explored in only one study to date in which students with developmental disabilities were not especially well represented (Savolainen et al., 2012). Thus, the aim of this study was to extend the study by Savolainen and colleagues (2012) to examine the relationship between teacher self-efficacy and teachers' sentiments, attitudes, and concerns about inclusive education, with a focus on students with developmental disabilities in one Canadian province. For the sake of comparison, the primary measures used by Savolainen et al. were also employed in this study. 
Teachers' Attitudes and Self-efficacy

\section{Method}

\section{Recruitment and Participants}

This study received approval from the Behavioural Research Ethics Board at the authors' University. Participants for this study were recruited through two provincial teacher associations in western Canada. An association representing primary grade teachers (grades K-3) sent out a letter of introduction and a web-based survey link to the email addresses of its members. In addition, the association included the survey link in their Fall 2012 newsletter, which was sent to all members. Additional participants were recruited through an association representing intermediate grade teachers (grades 4-7) at an annual 2-day conference in 2012 (attended by approximately 500 participants from across the province). Attendees who stopped by a research table were invited to complete surveys and return them either at the conference or by mail. Those who returned them during the conference were invited to enter their names into a lottery for four gift certificates from an online bookstore.

In total, 115 surveys were returned; of these, 100 were sufficiently complete to be included in the sample. Table 1 provides a summary of demographic information for the sample. Eightyseven percent of respondents were women; two-thirds were over the age of 35 and lived in the largest urban region of the province. Respondents' teaching assignments varied widely. Primary teachers accounted for $19.3 \%$ of the sample, intermediate teachers $67.5 \%$, special education teachers $8.4 \%$, and teachers who taught both primary and intermediate students accounted for $4.8 \%$. More than half $(55 \%)$ of respondents had 11 or more years of classroom teaching experience. While $61 \%$ of respondents had completed B.Ed. degrees as their highest level of education, $13 \%$ had also completed post-baccalaureate diplomas and 23\% had completed Masters degrees. Almost half (49.6\%) of respondents had completed 8 or more hours of in-service in special education in the past 5 years and $28.3 \%$ had completed 25 or more hours of such in-service. With the exception of students with dependent handicaps and those with deafblindness, most respondents had taught 1-9 students with developmental disabilities in various categories in the past 5 years.

\section{Measures}

Data were collected through both online and paper surveys that were preceded by an introductory letter informing participants that, by completing the survey, they agreed to the inclusion of their confidential data in the study. The surveys consisted of definitions that were relevant to the study, a brief demographic form, and two study measures.

Definitions. Respondents were provided with a definition of "developmental disability" at the beginning of each section of the survey: "A developmental disability is one that begins in childhood (before age 18), is life-long, and significantly affects intellectual capacity and/or adaptive skills. Some examples of developmental disabilities are: cerebral palsy, autism, Down syndrome, and intellectual disabilities." Respondents were directed to "Please keep this definition in mind when responding to the following questions/statements." Additional definitions were provided for the terms "general education" and "special education," using language that was familiar to teachers in the province. General education was defined as "a classroom taught by an enrolling teacher that may or may not include students with special needs." Special education was defined as "a program specifically developed for students with special needs (e.g., resource room, life skills program, etc.) or a program that services students with special needs and are taught by non-enrolling teachers (e.g., learning assistance).” 
Table 1

Participant Demographic Information

\begin{tabular}{|c|c|}
\hline Demographic Variable & $\begin{array}{l}\text { Percent of } \\
\text { Respondents }\end{array}$ \\
\hline \multicolumn{2}{|l|}{ Current teaching assignment } \\
\hline General education primary & 19.3 \\
\hline General education intermediate & 67.5 \\
\hline Special education & 8.4 \\
\hline General education primary and intermediate & 4.8 \\
\hline \multicolumn{2}{|l|}{ Sex } \\
\hline Men & 13.0 \\
\hline Women & 87.0 \\
\hline \multicolumn{2}{|l|}{ Age } \\
\hline$<25$ yrs & 2.0 \\
\hline $26-35$ yrs & 30.3 \\
\hline $36-45$ yrs & 24.2 \\
\hline $46+y r s$ & 43.0 \\
\hline \multicolumn{2}{|l|}{ Years of teaching } \\
\hline $0-5$ yrs & 28.0 \\
\hline $6-10 \mathrm{yrs}$ & 17.0 \\
\hline $11-20 \mathrm{yrs}$ & 26.0 \\
\hline $20+y r s$ & 29.0 \\
\hline \multicolumn{2}{|l|}{ Highest level of education } \\
\hline Bachelor of Education (B.Ed.) & 61.0 \\
\hline Diploma in special education & 3.0 \\
\hline Diploma (other) & 10.0 \\
\hline Masters in special education & 4.0 \\
\hline Masters (other) & 19.0 \\
\hline Other & 3.0 \\
\hline \multicolumn{2}{|l|}{ Hours of special education in-service training in past $5 \mathrm{yrs}$} \\
\hline 0 hours & 23.2 \\
\hline $1-7$ hours & 27.3 \\
\hline $8-15$ hours & 15.2 \\
\hline $16-25$ hours & 6.1 \\
\hline $25+$ hours & 28.3 \\
\hline \multicolumn{2}{|l|}{ \# of physically dependent students taught in past $5 \mathrm{yrs}$} \\
\hline 0 & 53.1 \\
\hline $1-9$ & 44.9 \\
\hline $10+$ & 2.0 \\
\hline \multicolumn{2}{|l|}{ \# of deafblind students taught in past $5 \mathrm{yrs}$} \\
\hline 0 & 80.0 \\
\hline $1-9$ & 20.2 \\
\hline $10+$ & 0.0 \\
\hline \multicolumn{2}{|c|}{ \# of students with moderate-profound intellectual disability taught in past $5 \mathrm{yrs}$} \\
\hline 0 & 40.6 \\
\hline $1-9$ & 55.2 \\
\hline & 4.0 \\
\hline \multicolumn{2}{|c|}{ \# of students with physical disabilities or chronic health impairments taught in past $5 \mathrm{yrs}$} \\
\hline 0 & 26.8 \\
\hline $1-9$ & 68.1 \\
\hline $10+$ & 5.0 \\
\hline
\end{tabular}

Demographic form. The demographic form consisted of closed-ended questions or statements designed to gather information related to participants' sex, age, educational background, years of teaching experience, current teaching assignment, amount of special education in-service completed in the past 5 years, and experience over the past 5 years with students with a range of developmental disabilities (e.g., moderate-profound intellectual disabilities, autism spectrum disorders, physical disabilities). 
Teacher Efficacy for Inclusive Practices (TEIP). The TEIP (Sharma et al., 2011) was originally developed to measure pre-service teachers' perceived self-efficacy for teaching in inclusive classrooms across three factors: efficacy in using inclusive instruction, efficacy in collaboration, and efficacy in managing problem behaviour. The final scale was tested on a sample of 609 pre-service teachers enrolled in teacher education programs at six universities across four countries (Canada, India, Hong Kong, and Australia). The scale uses a Likert-type scale from $1=$ strongly disagree to $6=$ strongly agree.

The TEIP scale has been found to be a reliable measure of pre-service teachers' feelings of self-efficacy toward inclusive education. Sharma et al. (2011) reported that the reliability coefficient for the total scale was $r=.89$; the three factors had coefficients of $r=.93, .85$, and .85 , respectively. The strong validity and reliability of the scale make it a good choice for measuring the self-efficacy of practicing teachers. The authors suggested this scale could be used by administrators and departments of education to "gauge an understanding of teacher efficacy of their teacher population to work effectively in inclusive classrooms, especially with new teachers, who may find inclusion challenging" (p. 6). The authors suggested that, based on the results of the scale, a learning program could be developed to address specific needs of practicing teachers.

Sentiments, Attitudes, and Concerns about Inclusive Education-Revised (SACIE-R). The original version of the SACIE-R (Forlin et al., 2011) contained items from three pre-existing surveys: the Attitudes Towards Inclusive Education scale; a modified version of the Interaction with Disabled Persons scale; and the Concerns about Inclusive Education Scale (Loreman, Earle, Sharman, \& Forlin, 2007). This instrument went through a number of refinements to produce the current 15 -item scale, which includes three sections. The Sentiments section measures how teachers feel about engaging with people with disabilities in general, the Attitudes section measures how teachers accept learners with different learning needs, and the Concerns section addresses the concerns that teachers may have about inclusive education. The SACIE-R employs a Likert-type scale from $1=$ strongly disagree to $4=$ strongly agree.

Most of the research related to the SACIE-R to date has been conducted with samples of pre-service teachers only. Forlin et al. (2011) evaluated the internal consistency of the SACIE-R with 542 pre-service teachers from nine institutions in four countries (Hong Kong, Canada, India, and the United States). The subscales (sentiments, attitudes, and concerns) had reliabilities of $r=.75, .67$, and .65 , respectively, and the overall scale had a reliability of $r=.74$. The authors suggested that the scale could be validated with other populations, including practicing teachers.

\section{Data Analysis}

Data from the surveys were analyzed using the Statistical Package for the Social Sciences (SPSS) software, version 16.0. Internal reliability coefficients for each factor of the study measures were first measured using Cronbach's alpha, a measure of internal consistency. Next, we measured the strength and direction of relationships between the TEIP factors and the SACIE-R factors using Pearson's product-moment correlations. This test is used to determine whether change (increase or decrease) in one variable is associated with change (increase or decrease) in another (Abu-Bader, 2011). The value of the coefficient indicates the strength of the relationship, while the positive or negative sign indicates the direction of the relationship. Finally, a series of multiple regression analyses were conducted (Brace, Kemp, \& Snelgar, 2012), with each of the SACIE-R subscales entered as the dependent variable and the TEIP subscales that were significantly correlated with each SACIE-R subscale entered as the independent varia- 
bles. This directional model was selected for two reasons. First, the sample size was too small to test a bidirectional model with sufficient power (Westland, 2010). Second, in practical terms, teacher self-efficacy is more malleable (i.e., through in-service training and coaching interventions designed to increase skills in areas where self-efficacy is low) than teachers' sentiments, attitudes, and concerns, which are likely to be more entrenched and difficult to change. Thus, we conducted the analyses in this study to determine which self-efficacy factors best explained Sentiments, Attitudes, and Concerns when examined simultaneously.

\section{Results}

The main purpose of this study was to examine relationships among factors related to teacher self-efficacy and teachers' sentiments, attitudes, and concerns about inclusive education. The first step was to determine the internal reliability of each factor on the TEIP and the SACIE$\mathrm{R}$ using data from the study sample. Cronbach's $\alpha$ coefficients are summarized in Table 2. DeVellis (2003) suggested that Cronbach's $\alpha$ coefficients of .65 or above provide evidence of at least "minimally acceptable" internal consistency of a scale or subscale. In this sample, $\alpha=.65-$ .76 for the three TEIP subscales and $\alpha=.68-.82$ for the three SACIE-R subscales. Thus, the individual items in each subscale measure a single underlying (i.e., latent) construct.

\section{Descriptive Statistics}

All three TEIP subscales employ positive statements related to teacher self-efficacy. For example, "I am confident in designing learning tasks so that the individual needs of students with disabilities are accommodated" (using inclusive instruction), "I can make parents feel comfortable coming to school" (collaboration), and "I can make my expectations clear about student behaviour" (managing problem behaviour). The highest possible score on each of the three TEIP subscales is 36 , with higher scores indicating higher perceived self-efficacy. In the present sample, the total mean scores were as follows: 28.1 for using inclusive instruction (range $=18-36$, $S D=3.70$ ); 28.3 for collaboration (range $=19-36, S D=3.38$ ); and 26.8 for managing problem behaviour (range $=14-36, S D=3.94$ ).

The Sentiments subscale of the SACIE-R employs negative statements to assess respondents' feelings about disability in general (e.g., "I dread the thought that I could eventually end up with a disability" and "I am afraid to look at a person with a disability"). The highest possible score on the subscale is 20 . In the present sample, the mean score was 9.1 (range $=5-17, S D=$ 2.29). Because higher scores are indicative of negative attitudes about people with disabilities in general, negative correlations with the three TEIP self-efficacy factors are desirable.

Table 2

Cronbach's Alpha Results for the TEIP and SACIE-R Factors

\begin{tabular}{|c|c|c|c|}
\hline \multicolumn{2}{|l|}{ Scale Factors } & \multirow[t]{2}{*}{$\begin{array}{l}\text { Cronbach's } \\
\text { alpha }\end{array}$} & \multirow[t]{2}{*}{ Interpretation } \\
\hline & TEIP & & \\
\hline Self-efficacy in using inclusive instruction & & .76 & Respectable \\
\hline Self-efficacy in managing disruptive behaviour & & .77 & Respectable \\
\hline Self-efficacy in collaboration & & .65 & Minimally acceptable \\
\hline & SACIE-R & & \\
\hline Sentiments & & .68 & Minimally acceptable \\
\hline Attitudes & & .82 & Very Good \\
\hline Concerns & & .79 & Respectable \\
\hline
\end{tabular}


The Attitudes subscale of the SACIE-R employs positive statements that endorse the belief that students with (in the present study) developmental disabilities should be included in regular education classrooms (e.g., "Students who have difficulty expressing their thoughts verbally should be in regular classes" and "Students who need an individualized academic program should be in regular classes"). The highest possible score on the subscale is 20 . In the present sample, the mean score was 15.3 (range $=7-20, S D=2.57$ ). Because higher scores on this subscale are indicative of positive attitudes about including students with disabilities, positive correlations with the three TEIP self-efficacy factors are desirable.

Finally, like the Sentiments subscale of the TEIP, the Concerns subscale provides negative statements about potential barriers that teachers may experience (e.g., "I am concerned that it will be difficult to give appropriate attention to all students in an inclusive classroom" and "I am concerned that my workload will increase if I have students with disabilities in my class"). The highest possible score on the subscale is 20. In the present sample, the mean score was 13.9 (range $=5-20, S D=3.14$ ). Because higher scores on this subscale indicate greater concerns, negative correlations with the three TEIP self-efficacy factors are desirable.

\section{Correlations}

Table 3 summarizes the results of the Pearson product-moment correlation analyses related to the research question.

Sentiments. As noted previously, negative correlations between the three TEIP subscales and the Sentiments subscale are desirable. The results suggest a weak but statistically significant negative relationship between Sentiments and teachers' self-efficacy related to collaboration, and very weak but significant negative relationships between Sentiments and teachers' self-efficacy for using inclusive instruction and managing problem behaviour. In other words, teachers with more positive sentiments about people with disabilities in general tended to feel more confident in their ability to collaborate and (to a lesser degree) to use inclusive instruction and manage problem behaviour of students with developmental disabilities.

Attitudes. As noted previously, positive correlations between the three TEIP subscales and the Attitudes subscale are desirable. The results suggest weak but statistically significant positive relationships between Attitudes and teachers' self-efficacy related to using inclusive instruction and collaborating, and a very weak but significant positive relationship between Attitudes and teachers' self-efficacy for managing problem behaviour. In other words, teachers with more positive attitudes about including students with developmental disabilities tended to feel more confident in their ability to use inclusive instructional practices and collaborate and (to a lesser degree) to manage problem behaviour.

Table 3

Correlations Between Teachers' Self-efficacy and Teachers' Sentiments, Attitudes, and Concerns

\begin{tabular}{lccc}
\hline \multicolumn{1}{c}{ TEIP Factors } & \multicolumn{3}{c}{ SACIE-R Factors } \\
\cline { 2 - 4 } & Sentiments & Attitudes & Concerns \\
\hline Using inclusive instruction & $-.215^{*}$ & $.339^{* *}$ & $-.480^{* *}$ \\
Collaboration & $-.450^{* *}$ & $.373^{* *}$ & $-.561^{* *}$ \\
Managing problem behaviour & $-.245^{*}$ & $.235^{*}$ & $-.484^{* *}$ \\
\hline${ }^{*} p<.05 ;^{* *} p<.01$. & &
\end{tabular}


Concerns. As noted previously, negative correlations between the three TEIP subscales and the Concerns subscale are desirable. As displayed in Table 3, a moderate statistically significant negative relationship was found between Concerns and teachers' self-efficacy related to collaboration, and weak but significant negative relationships were evident between Concerns and teachers' self-efficacy for using inclusive instruction and managing problem behaviour. In other words, teachers with fewer concerns about including students with developmental disabilities tended to feel more confident in their ability to collaborate and (to a lesser degree) to use inclusive instructional practices and manage problem behaviour.

\section{Multiple Regression Analysis}

Because all the TEIP factors correlated with the SACIE-R variables, we conducted a series of multiple regressions using the Enter method in SPSS to determine which TEIP factors best explained Sentiments, Attitudes, and Concerns (the criterion variables). Collinearity statistics for all three analyses revealed acceptable tolerance values, indicating that the predictor variables (i.e., TEIP factors) were not correlated to an unacceptable degree. Results of the multiple regression analyses are summarized in Table 4.

In all three models, teachers' self-efficacy for collaboration emerged as the only significant predictor of Sentiments, Attitudes, and Concerns, when all three self-efficacy factors were considered simultaneously. Neither teacher self-efficacy for using inclusive instruction nor teacher self-efficacy for managing problem behaviour were significant predictors in this model. The Adjusted $\mathrm{R}$ square values indicate that collaboration accounted for $14 \%, 13.6 \%$, and $33.8 \%$ of the variance in the three criterion variables, respectively.

\section{Discussion}

Both teachers' self-efficacy and teachers' attitudes, among other variables, have been identified as key factors that influence the success of inclusion. Sharma et al. (2011) used the TEIP to measure pre-service teachers' self-efficacy in using inclusive instruction, collaboration, and managing disruptive behaviour, and Forlin et al. (2011) used the SACIE-R to measure preservice teachers' sentiments, attitudes, and concerns about inclusive education. Savolainen et al. (2012) used both scales in a study of practicing teachers in Finland and South Africa. The current study aimed to replicate and extend previous findings by exploring the relationships between practicing teachers' self-efficacy and their attitudes, sentiments, and concerns towards inclusive education for a subset of the disability population - those with developmental disabilities.

Like Wilkins and Nietfeld's (2004) research, this study found that teachers who were confident (i.e., higher self-efficacy) in their ability to provide inclusive education had more positive feelings about inclusion in general. This was true for each of the three components of selfefficacy we examined: using inclusive instruction, collaborating with others, and managing disruptive behaviour. However, perhaps the most significant finding of this study is the importance of teachers' feelings of self-efficacy with regard to collaboration that emerged in the regression

Table 4

Results of Multiple Regression Analyses

\begin{tabular}{lccccccc}
\hline Criterion variable (SACIE-R) & $d f$ & $F$ & $p$ & Adjusted $\mathrm{R}^{2}$ & Predictor variable(s) (TEIP) & $\beta$ & $p$ \\
\hline Sentiments & 3,86 & 5.83 & .001 & .140 & Collaboration & -.416 & .002 \\
Attitudes & 3,86 & 5.65 & .001 & .136 & Collaboration & .317 & .014 \\
Concerns & 3,90 & 16.84 & .0005 & .338 & Collaboration & -.368 & .001 \\
\hline
\end{tabular}


analysis. When considered together with the other components that were measured (i.e., the ability to use inclusive instruction and manage disruptive behaviour), only teacher self-efficacy with regard to collaboration significantly explained sentiments, attitudes, and concerns about inclusive education. This finding replicates that of Savolianen et al. (2012), which involved larger samples of teachers whose responses were not focused solely on inclusion of students with developmental disabilities. The similarity of this finding across two very different studies that represent samples from three countries (Canada, Finland, and South Africa) lends weight to its credibility.

\section{Effective Collaboration}

In inclusive classrooms, teachers are called upon to consult and collaborate with a wide variety of professionals and others - including parents - on a regular basis and in a variety of ways. Teachers who do not feel confident working with other adults in and out of the classroom may feel more apprehensive and, as a result, more negative about inclusive education. Effective collaboration requires that a team of professionals and parents work together to design, implement, and evaluate appropriate educational goals for students with disabilities. Research has identified the benefits of collaboration in inclusive education. Cahill and Mitra (2008) noted that collaboration between teachers (particularly general and special education teachers) is an important strategy for supporting student learning in inclusive settings. Similarly, Santoli, Sachs, Romey, and McClurg (2008) found that collaboration is critical for ensuring that students receive appropriate educational programming and services. For example, through collaboration and teamteaching, special education teachers have opportunities to share disability-specific knowledge as well as best practices in instructional strategies for students with special needs with their general education teaching partners. In addition, when general and special education teachers collaborate, they can work together to learn new instructional approaches and increase their understanding of inclusive education (Cahill \& Mitra, 2008).

Collaboration with parents can also enable teachers to increase their knowledge about individual disabilities and student needs. In Tucker and Schwartz's (2013) study, parents of students with autism spectrum disorders, their teachers, and their principals were asked about their perceptions of collaboration. Parents identified the importance of having professionals who understood the importance of their children's lives outside of school when planning Individual Education Plan goals. Parents are in a unique position to provide specific information about their child's disability as well as the goals that are important to them, including goals for family and community settings. Parents may also request the input of professionals from outside agencies, which can further increase educators' knowledge of students and their needs (Tucker \& Schwartz, 2013).

\section{Barriers to Collaboration}

Despite the benefits of collaboration, several barriers restrict its use and effectiveness. Many teachers and school teams struggle to implement collaborative practices and collaborative decision-making, perhaps because of confusion over professional roles and responsibilities. General and special education teachers often have specific sets of skills and knowledge that benefit programming for students with special needs, but may not understand one another's roles in an inclusive classroom. It is necessary for teams to understand the roles of teachers in both of these roles (Cahill \& Mitra, 2008; Tucker \& Schwartz, 2013) and for all parties to understand that general and special education teachers are jointly responsible for student instruction (Smith \& Leonard, 2005). 
Another barrier to collaboration is that teachers often lack training in effective collaboration and communication skills. When working with a team to develop goals and strategies for learning, effective communication is essential; thus, it is important for teachers to be provided with opportunities to develop their collaboration and problem-solving skills (Smith \& Leonard, 2005). Some of the key skills necessary for effective collaboration include active listening, empathy, assertiveness, and negotiation (Solis, Vaughn, Swanson, \& McCulley, 2012). It is also important that school teams communicate effectively with parents. In one study (i.e., Tucker \& Schwartz, 2013), 66\% of parents of students with autism reported that there had been at least one time when they were not involved in planning for their child's programming. Professional development in communication and collaboration, including strategies for working with parents, should be priorities in inclusive schools.

The logistics of collaboration can also prevent its regular and effective use in schools. In order for collaboration to be successful, time is needed for meetings between members. Smith and Leonard (2005) noted the importance of administrators who have a commitment to collaboration and who provide time for meetings among staff and other professionals. Time was also identified as an essential component of successful collaboration by several other researchers as well (e.g., Cahill \& Mitra, 2008; Santoli et al., 2008).

A final barrier to collaboration may relate to the input of professionals from agencies and service providers outside the school system. Many students with disabilities are involved in therapy and treatment programs outside of school, and parents often want professionals from these programs to attend school-based team meetings. For instance, behaviour specialists, speechlanguage pathologists, and other consulting professionals may be asked to identify important goals for inclusion on a student's Individual Education Plan. In addition, Tucker and Schwartz (2013) noted that some parents value the advice of a third party advocate when faced with a communication breakdown with their school team. School teams may be reticent to include input from outside service providers because their goals may not match the school goals or may require expertise that is not readily available in a school setting. These outside providers, however, often are able to provide extra information that may be useful to the school team.

\section{Collaboration and Professional Development}

The challenges of collaboration are not new and have been at the forefront of educational policy discussions in recent years. For example, in 2006, Hewko v. B.C., 2006 BCSC 1638 drew national attention to the issue of meaningful consultation and collaboration with parents and outside service providers. Darren Hewko was a kindergarten student with autism in a school district during the 2002/2003 school year and was involved in a home-based applied behaviour analysis program. The school district decided that Darren would be placed in a resource room for his Grade 1 year and refused to allow his home-based applied behaviour analysis providers to consult with school staff. When his parents lost their appeal of this decision, they filed a lawsuit, alleging that Darren was discriminated against because of his disability and that the school district was negligent in their duties under the School Act. While the judge did not find that Darren had been discriminated against, she did find "that the... School District breached its statutory duty to meaningful consult with the Hewkos about Darren Hewko's education placement and program" (p. 114).

If in-service training is related to teachers' self-efficacy in collaboration-as the results of this study suggest - and if self-efficacy is related to teachers' sentiments, attitudes, and concerns about inclusive education, then providing effective and adequate professional development on 
collaboration should be a major focus for districts and provincial ministries of education. For example, in response to the Hewko decision, the British Columbia Council of Administrators of Special Education (2008) produced a resource manual for teachers and educational staff entitled, "Supporting Meaningful Consultation with Parents." Yet, professional development opportunities for collaboration are still lacking in British Columbia and elsewhere. At the Provincial Intermediate Teachers' Association conference in Fall 2012, for example, 70 workshops were offered over the course of 2 days, but not one focused on strategies for collaboration, collaborative teaming, or working with parents. At the British Columbia Special Education Association's annual conference in 2013, only one workshop (of 11) addressed strategies for collaboration; another focused on transition planning that included teachers, parents, and students, but no mention was made of the specific skills required for collaboration. From these recent examples, it appears that professional development opportunities to learn about effective collaboration are not readily available to many teachers. This study's results highlight the critical need for such information.

\section{Limitations}

Like all research, this study has a number of limitations. As with most survey-based studies, there may have been some self-selection bias because all of the participants volunteered to complete the survey. In addition, only members of the two provincial elementary teacher associations were invited to participate; thus, the results do not apply to teachers in secondary schools (grades 8-12). However, since participants of these two organizations represent teachers from across the province, and since teachers from all regions of the province were included in the sample, the results may be representative of the larger provincial population of primary and intermediate-level teachers.

Another limitation of this study is the small sample size; only 100 primary, intermediate, and special education teachers completed the survey, which restricts the conclusions that can be drawn. In addition, the two scales used in this study (the TEIP and SACIE-R) were developed for use with pre-service teacher populations and have only been used to measure practicing teachers' attitudes and self-perceptions in one previous study (Savolainen et al., 2012). However, both Sharma et al. (2011) and Forlin et al. (2011) suggested the scales could be used with practicing teacher populations. While the reliability coefficients for two of the subscales were only marginally acceptable, results suggest the scales can be used to measure teachers' self-efficacy and sentiments, attitudes, and concerns about inclusive education. However, additional research with larger sample sizes is required to explore this finding across a wider range of practicing teachers.

\section{Conclusion}

This study makes an important contribution to research on teachers' self-efficacy and sentiments, attitudes, and concerns about inclusive education for students with developmental disabilities. It is one of the few studies that has assessed the reliability of the TEIP and SACIE-R with in-service teachers. In addition, the study replicates a previous finding (Savolainen et al., 2012) that teachers' self-efficacy with regard to collaboration is primarily associated with positive sentiments and attitudes and fewer concerns about inclusive education. The study sheds light on the importance of training in the area of collaboration as a contributor to the implementation of inclusive educational practices for students with developmental disabilities. Future research is needed to determine the content and format (e.g., workshops, in vivo coaching, modeling) of inservice training that can be provided to develop teachers' self-efficacy in the area of collaboration. 


\section{References}

Abu-Bader, S. H. (2011). Using statistical methods in social science research with a complete SPSS guide (2nd ed.). Chicago, IL: Lyceum Books.

Blecker, N. S., \& Boakes, N. J. (2010). Creating a learning environment for all children: Are teachers able and willing? International Journal of Inclusive Education, 14, 435-447. doi:10.1080/13603110802504937

Brace, N., Kemp, R., \& Snelgar, R. (2012). SPSS for psychologists. New York, NY: Palgrave Macmillan.

British Columbia Council of Administrators of Special Education. (2008, April). Supporting meaningful consultation with parents. Retrieved from http://sd41.bc.ca/learning_support/pdf/meaningfulConsultation .puff

British Columbia Ministry of Education. (2013, January). Student statistics - 2012-2013. Retrieved from http://www.bced.gov.bc.ca/reports/pdfs/student stats/prov.pdf.

Cahill, S. M., \& Mitra, S. (2008). Forging collaborative relationships to meet the demands of inclusion. Kappa Delta Pi Record, 44, 149-151. doi:10.1080/00228958.2008.10516513

Canadian Council on Learning. (2009, March 18). Lessons in learning: Does placement matter? Retrieved from http://www.ccl-cca.ca/pdfs/LessonsInLearning/03_18_09E.pdf.

Cook, B. G., \& Cameron, D. L. (2010). Inclusive teachers' concern and rejection toward their students: Investigating the validity of ratings and comparing student groups. Remedial and Special Education, 31, 6776. doi: $10.1177 / 0741932508324402$

Cook, B. G., Tankersley, M., Cook, L., \& Landrum, T. J. (2000). Teachers' attitudes toward their included students with disabilities. Exceptional Children, 67, 1-15. Retrieved from http://journals.cec.sped .org/ec/

Daane, C. J., Beirne-Smith, M., \& Latham, D. (2001). Administrators' and teachers' perceptions of the collaborative efforts of inclusion in the elementary grades. Education, 121, 331-338. Retrieved from http://www .projectinnovation.com/Education.html

de Boer, A., Pijl, S. J., \& Minnaert, A. (2011). Regular primary school teachers' attitudes towards inclusive education: A review of the literature. International Journal of Inclusive Education, 15, 331-353. doi:10.1080/13603110903030089

Dessemontet, R. S., Bless, G., \& Morin, D. (2012). Effects of inclusion on the academic achievement and adaptive behaviour of children with intellectual disabilities. Journal of Intellectual Disability Research, 56, 579-587. doi:10.1111/j.1365-2788.2011.01497.x

DeVellis, R. F. (2003). Scale development (2nd ed.). Thousand Oaks, CA: Sage Publications.

Forlin, C., Earle, C., Loreman, T., \& Sharma, U. (2011). The sentiments, attitudes, and concerns about inclusive education revised (SACIE-R) scale for measuring pre-service teachers' perceptions about inclusion. Exceptionality Education International, 21, 50-65. Retrieved from http://ir.lib.uwo.ca/eei/

Gilmore, L., Campbell, J., \& Cuskelly, M. (2003). Developmental expectations, personality stereotypes, and attitudes towards inclusive education: Community and teacher views of Down syndrome. International Journal of Disability, Development, and Education, 50, 65-76. doi:10.1080/1034912032000053340

Hammond, H., \& Ingalls, L. (2003). Teachers' attitudes toward inclusion: Survey results from elementary school teachers in three southwestern rural school districts. Rural Special Education Quarterly, 22, 24 30. Retrieved from http://acres-sped.org/journal

Hewko v. B.C., 2006. BCSC 1638. Retrieved from http://www.canlii.org/en/bc/bcsc/doc/2006/2006bcsc1638 /2006bcsc1638.html.

Horne, P. E., \& Timmons, V. (2009). Making it work: Teachers' perspectives on inclusion. International Journal of Inclusive Education, 13, 273-286. doi:10.1080/13603110701433964

Jordan, A., Schwartz, E., \& McGhie-Richmond, D. (2009). Preparing teachers for inclusive classrooms. Teaching and Teacher Education, 25, 535-542. doi:10.1016/j.tate.2009.02.010

Katz, J., \& Mirenda, P. (2002a). Including students with developmental disabilities in general education classrooms: Educational benefits. International Journal of Special Education, 17, 14-25. Retrieved from $\mathrm{http} / / / \mathrm{www}$. internationaljournalofspecialeducation.com/

Katz, J., \& Mirenda, P. (2002b). Including students with developmental disabilities in general education classrooms: Social benefits. International Journal of Special Education, 17, 26-36. Retrieved from $\mathrm{http} / / / \mathrm{www}$.internationaljournalofspecialeducation.com/ 
Kent-Walsh, J. E., \& Light, J. C. (2003). General education teachers' experiences with inclusion of students who use augmentative and alternative communication. Augmentative and Alternative Communication, 19, 104-124. doi:10.1080/0743461031000112043

Kugelmass, J. W. (2001). Collaboration and compromise in creating and sustaining an inclusive school. International Journal of Inclusive Education, 5, 47-65. doi:10.1080/13603110121498

Lohrmann, S., \& Bambara, L. M. (2006). Elementary education teachers' beliefs about essential supports needed to successfully include students with developmental disabilities who engage in challenging behaviors. Research \& Practice for Persons with Severe Disabilities, 31, 157-173.

Loreman, T., Earle, C., Sharma, U., \& Forlin, C. (2007). The development of an instrument for measuring preservice teachers' sentiments, attitudes, and concerns about inclusive education. International Journal of Special Education, 22, 1-16. Retrieved from http://www.internationaljournalofspecialeducation.com/

McDonnell, J., Thorson, N., Disher, S., Mathot-Bucker, C., Mendel, J., \& Ray, L. (2003). The achievement of students with developmental disabilities and their peers without disabilities in inclusive settings: An exploratory study. Education and Treatment of Children, 26, 1-8. Retrieved from http://www .educationandtreatmentofchildren.net/

Monahan, R. G., Marino, S. B., \& Miller, R. (1996). Teacher attitudes toward inclusion: Implications for teacher education in schools 2000. Education, 117, 316-320. Retrieved from http://www .projectinnovation.com/Education.html

Santoli, S. P., Sachs. J., Romey, E. A., \& McClurg, S. (2008). A successful formula for middle school inclusion: Collaboration, time, and administrative support. Research in Middle Level Education, 32, 1-13. Retrieved from http://www.amle.org/ServicesEvents/ResearchinMiddleLevelEducationOnline/tabid/173 /Default.aspx

Savolainen, H., Englebrecht, P., Nel, M., \& Malinen, O-P. (2012). Understanding teachers' attitudes and selfefficacy in inclusive education: Implications for pre-service and in-service teacher education. European Journal of Special Needs Education, 27, 51-68. doi:10.1080/08856257.2011.613603

Sharma, U., Loreman, T., \& Forlin, C. (2011). Measuring teacher efficacy to implement inclusive practices. Journal of Research in Special Educational Needs, 12, 12-21. doi:10.1111/j.1471-3802.2011.01200.x

Smith, R., \& Leonard, P. (2005). Collaboration for inclusion: Practitioner perspectives. Equity \& Excellence in Education, 38, 269-279. doi:10.1080/10665680500299650

Solis, M., Vaughn, S., Swanson, E., \& McCulley, L. (2012). Collaborative models of instruction: The empirical foundations of inclusion and co-teaching. Psychology in Schools, 49, 498-510. doi:10.1002/pits .21606

Soto, G., Müller, E., Hunt, P., \& Goetz, L. (2001). Critical issues in the inclusion of students who use augmentative and alternative communication: An educational team perspective. Augmentative and Alternative Communication, 17, 62-72. Retrieved from http://informahealthcare.com/journal/aac

Statistics Canada. (2007). Participation and Activity Limitation Survey (PALS) 2006 (Data file). Retrieved from http://www.statcan.gc.ca/pub/89-628-x/89-628-x2010015-eng.htm.

Timmons, V. (2006). Impact of a multipronged approach to inclusion: Having all partners on side. International Journal of Inclusive Education, 10, 469-480. doi:10.1080/13603110500392726

Tucker, V., \& Schwartz, I. (2013). Parents' perspectives of collaboration with school professionals: Barriers and facilitators to successful partnerships in planning for students with ASD. School Mental Health, 112. doi:10.1007/s12310-012-9102-0

Westland, J. C. (2010). Lower bounds on sample size in structural equation modeling. Electronic Commerce Research and Applications, 9, 476-487. doi:10.1016/j.elerap.2010.07.003

Wilkins, T., \& Nietfeld, J. L. (2004). The effect of a school-wide training programme upon teachers' attitudes about inclusion. Journal of Research in Special Educational Needs, 4, 115-121. doi:10.1111/j.14713802.2004.00026.x

\section{Authors' Note}

Correspondence concerning this article should be addressed to Pat Mirenda, University of British Columbia, 2125 Main Mall, Vancouver, BC, V6T 1Z4, Canada. Email: pat.mirenda@ubc.ca 